\title{
Determination of the Crust and Upper-Mantle Structure in Anatolia by Surface Wave Data
}

\author{
Nilgun Sayil \\ Department of Geophysics, Engineering Faculty, Karadeniz Technical University, Trabzon, Turkey \\ Email: sayil@ktu.edu.tr
}

Received 10 June 2014; revised 12 July 2014; accepted 20 July 2014

Copyright (C) 2014 by author and Scientific Research Publishing Inc. This work is licensed under the Creative Commons Attribution International License (CC BY). http://creativecommons.org/licenses/by/4.0/ (c) (i) Open Access

\begin{abstract}
In this study, the crust and upper mantle structure of Anatolia have been investigated by measuring the group velocity dispersion data of discriminated seismic surface waves. In the scope of the study, it has selected the profiles between six stations located in western Anatolia of Bogazici University Kandilli Observatory Earthquake Research Institute, national network of Turkey, and records of an earthquake (having about $10^{\circ}$ epicentral distance) occurred in the eastern of Anatolia have been used. Firstly, surface wave discrimination filter based on the polarization properties has been applied to three-component records and emphasized to surface waves. Then the group velocities have been calculated by multiple filter technique. A five-layered crustal model having total thickness of $38-40 \mathrm{~km}$ and Pn-wave velocity of $8.00 \mathrm{~km} / \mathrm{sec}$ in the upper-mantle has been determined through inversion of surface wave group velocity dispersion data in the period range of $10 \mathrm{sec}$ to $60 \mathrm{sec}$.
\end{abstract}

Keywords

Anatolia, Group Velocity Dispersion, Surface Waves, Discrimination Filter

\section{Introduction}

The differences between polarization properties of surface waves and microseismic noise allow filtering a type of the desired surface waves on three-component records [1]-[8]. Surface wave data have been used to define the earth structure on different propagating paths. The parameters as group arrival times, phase angles and amplitude values of surface waves are used to research elastic properties of the earth. In order to determine parameters as particle motion, phase and group velocity, single-station, two-station, and three- or more station methods can 
be used. The simplest one is a single-station method [9] [10]. Source effect is large on phase delays. And it also decreases while period increases. Therefore, the source functions are not considered for group velocity solutions for about $10^{\circ}$ epicenter records on which periods are large enough [11] [12].

Turkey and the surrounding regions are one of the most active regions in the world and have active and complex tectonics including plate subduction, collision, extension, crustal thickening and high seismicity. A number of large-scale surface and body wave studies in the region provide insight to the overall complexity of the Mediterranean region [13]-[26], in Alpine-Himalayan with body waves [27]-[31] and in Turkish-Iranian Plateau with surface waves [32] [33], with body waves [34] [35]. Reference [36] inferred a crustal thickness of $38 \mathrm{~km}$ in northern and eastern Anatolia from the dispersion of Love waves. Reference [37] found an uppermost mantle Pn-wave velocity of $8.1 \mathrm{~km} / \mathrm{sec}$ for western Turkey and $7.9 \mathrm{~km} / \mathrm{sec}$ for eastern Turkey using travel times and station residuals of P-waves and phase and group velocities of surface waves. Reference [38] found the crust thickness of $40 \mathrm{~km}$ and upper mantle shear velocity of $4.2 \mathrm{~km} / \mathrm{sec}$ throughout all Turkey. Reference [39] obtained Pn-wave velocity of $7.99 \mathrm{~km} / \mathrm{sec}$ from reciprocal profiles in N-S direction for east Anatolia and Pn-wave velocity of $7.93 \mathrm{~km} / \mathrm{sec}$ from single side profile in N-S direction for west using single-station travel time method. They also found Pn-wave velocity of $8.00 \mathrm{~km} / \mathrm{sec}$ for profiles in E-W direction used by station pairs located in west and east Anatolia and the crust thickness of $38 \mathrm{~km}$ for Anatolia. The teleseismic P-wave tomography by [31] has a good lateral resolution mainly beneath Anatolia. Previous local surface wave studies have been limited by relatively sparse or non-uniform station coverage. These studies highlight the existence of strong differences in mantle shear velocities in different parts of our study area [22] [25] [40]. A 3-D upper-mantle structure beneath Turkey is investigated by [24] using phase speeds of fundamental-mode Rayleigh waves employing a conventional two-station method with high-density seismic networks in Turkey and the three-dimensional S-wave model was obtained in the depth range of 40 to $180 \mathrm{~km}$ using the phase velocity maps in the period range of 25 to $120 \mathrm{~s}$. Maximum S-wave velocity was found in the interval of $4.5-4.7 \mathrm{~km} / \mathrm{sec}$ in the depth range of $50-150 \mathrm{~km}$ for Turkey. They also found that the S-wave velocities are generally faster in the west and become slower in the east of Turkey. They suggested that, it will be better to use alternative methods as surface wave group velocity and ambient noise tomography that can be more sensitive to shallow structures to better constrain the crustal structure of Turkey with higher horizontal resolution. Reference [41] proposed a model consisting of a sediment cover of about $2 \mathrm{~km}$ thick with a velocity of $3.6 \mathrm{~km} / \mathrm{sec}$, an upper crystalline crust down to $13 \mathrm{~km}$ with $5.9 \mathrm{~km} / \mathrm{sec}$, and a middle crust down to $25 \mathrm{~km}$ depth with $6.5 \mathrm{~km} / \mathrm{sec}$ according to the seismic experiment performed in the east of Marmara. Reference [42] modeled a sedimentary sequence with velocities of 4.0 - $5.0 \mathrm{~km} / \mathrm{sec}$ using 2-D tomographic seismic velocity image in the eastern Marmara region along an N-S trending seismic refraction profile with reversal shots, which traverses the northern strand of the NAFZ.

In this study, the crust and upper mantle structure of Anatolia have been investigated by measuring the group velocity dispersion data of discriminated seismic surface waves. Earthquakes occurred in eastern and western of Anatolia have good locations to construct the profiles across Anatolia. Long-period three-component seismograms of an earthquake (EZM) occurred in eastern Anatolia, recorded at KOERI (Bogazici University Kandilli Observatory and Earthquake Research Institute, Turkey) stations located in western Anatolia of an earthquake (EZM) occurred in eastern Anatolia have been used. To improve the definition of surface waves, discrimination filter based on the polarization properties introduced by [2] has been applied to the three-component records of all stations. Multiple filter technique (MFT) has been used for compute to the group velocities from discriminated surface waves. The crust and upper mantle structure for profiles between event and station have been determined by inversion process using these group velocities.

\section{Methods}

\subsection{Surface Wave Discrimination Filter Based on Polarization Properties}

Filtering process is performed in the frequency domain since surface waves are dispersive. The discrete Fourier transforms of vertical, radial and tangential components of the ground motion are computed for a selected window length and moving interval. The amplitude coefficients at each frequency are weighted according to how closely the three-dimensional particle motion pattern at that frequency corresponds to theoretical patterns for Love and Rayleigh waves, while weights or adjustments are not applied to the original phase values. Weighted segments for each window are transformed to the time domain, and filtered signal is obtained as the arithmetic average of values of the overlapping amplitudes [2]. 
The components of the ground motion at time interval with length of $N \Delta t$ ( $\Delta t$ is sampling rate) are derived from kinds of discrete Fourier coefficients using Equations (1) and (2).

$$
\begin{gathered}
A_{i}(\eta f)=\left[a_{i}^{2}(\eta f)+b_{i}^{2}(\eta f)\right]^{1 / 2} \\
\Phi_{i}(\eta f)=\arctan \left[\frac{b_{i}(\eta f)}{a_{i}(\eta f)}\right], \eta=0,1,2, \cdots, N / 2
\end{gathered}
$$

where $i=Z, R, T$ represents the vertical, radial and tangential components of the ground motion, respectively. The apparent horizontal azimuth $\beta(\eta f)$, the angle $\psi(\eta f)$ between the major eccentricity of the particle motion ellipse and vertical component and the phase difference $\alpha(\eta f)$ between the vertical and radial components of the ground motion are determined as Equations (3)-(5), respectively (Figure 1).

$$
\begin{gathered}
\beta(\eta f)=\arctan \left[\frac{A_{T}(\eta f)}{A_{R}(\eta f)}\right] \\
\psi(\eta f)=\arctan \left[\frac{\sqrt{A_{R}^{2}(\eta f)+A_{T}^{2}(\eta f)}}{A_{Z}(\eta f)}\right] \\
\alpha(\eta f)=\varphi_{R}(\eta f)-\varphi_{Z}(\eta f)
\end{gathered}
$$

The amplitude coefficient of the each harmonic of the ground motion components can be weighted using function $\beta(\eta f), \psi(\eta f)$ and $\alpha(\eta f)$ as in Equation (6).

$$
\begin{gathered}
A_{Z}^{\prime}(\eta f)=A_{Z}(\eta f) \cdot \cos ^{M}[\beta(\eta f)] \cdot \cos ^{K}[\psi(\eta f)-\theta] \cdot \sin ^{N}[\alpha(\eta f)] \\
A_{R}^{\prime}(\eta f)=A_{R}(\eta f) \cdot \cos ^{M}[\beta(\eta f)] \cdot \cos ^{K}[\psi(\eta f)-\theta] \cdot \sin ^{N}[\alpha(\eta f)] \\
A_{T}^{\prime}(\eta f)=A_{T}(\eta f) \cdot \sin ^{M}[\beta(\eta f)] \cdot \sin ^{K}[\psi(\eta f)]
\end{gathered}
$$

where $A_{Z}^{\prime}(\eta f), A_{R}^{\prime}(\eta f)$ and $A_{T}^{\prime}(\eta f)$ are the weighted vertical, radial and tangential components of the ground motion. The functions $\beta(\eta f), \psi(\eta f)$ and $\alpha(\eta f)$ vary from 0 to 1 . The exponents $M, K$ and $N$ are empirical constants. The angle $\theta$ can be selected in situation that must protect a specific horizontal/vertical displacement ratio.

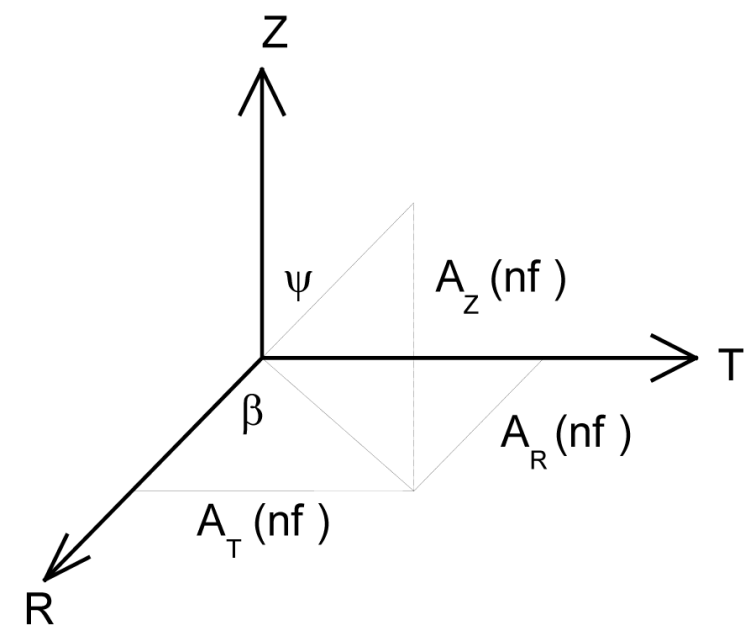

Figure 1. The relation between the apparent horizontal azimuth $(\beta)$, the eccentricity $(\psi)$ and three orthogonal components of ground motion $\left(A_{R}(\eta f), A_{r}(\eta f), A_{z}(\eta f)\right)$. 


\subsection{Multiple Filter Technique (MFT)}

MFT can resolve complex transient signals composed of several dominant periods that arrive at the recording station almost simultaneously. The basis of MFT is to determine amplitude changes of the signal as a function of velocity and period (Figure 2). Window function and velocity change should have a high resolution. Gauss function is appropriate as a window function. Filtering in frequency domain is preferred since it has higher resolution and saves CPU time. At the end of each multiple filtering, group velocity is computed from the wavelet obtained by the inverse Fourier transform for a corresponding period [43]-[45].

\subsection{The "Hedgehog" Non-Linear Inversion Method}

In the trial and error Hedgehog method [46] [47], that represents an optimized Monte Carlo search, the unknown structural Earth model is replaced by set of parameters, therefore the retrieval of the model is reduced to the determination of the numerical values of the parameters. Limits and increment amounts of the parameters are determined to construct the theoretical model for the each iteration of inversion. When the differences between observed and theoretical group velocities within the acceptable error limits, the structure model obtained from theoretical group velocities is taken as a searching structure. Therefore the problem is reduced to find the zone of minimum of a multidimensional function in the space of the unknown parameters of the cross-section and it is independent from the starting solution. In the elastic approximation, the unknown earth model is divided into a stack of homogeneous isotropic layers. Each layer is defined by a number of physical functions: S-wave velocity and thickness of the layers (independent parameters), P-wave velocity (dependent parameter, Poissonian relation between $V_{P}$ and $V_{S}$ ) and density (fixed parameter). The range of variability of the independent parameters is fixed according to the available geophysical information (the seismic refraction and reflection profiles that cross the studied region as well as other geophysical information available from literature are used to fix the thickness and the P-wave velocities in the uppermost crustal layers) and the parameterization is controlled by the resolving power of the data [48]. In general solids are assumed to be Poissonian and the density is estimated using the Nafe-Drake relation [49].

\section{Application of Methods}

Earthquakes occurred in east and west Anatolia has good locations to construct the profiles that cover the Turkey. To create these profiles, long-period three component digital records at six stations (YLVX, MRMX, MLSB, ISP, ISK, EDRB) of KOERI network having about $10^{\circ}$ epicentral distance of an earthquake (event code: EZM, date: 25.03 .2004 , epicenter coordinates: $39.92^{\circ} \mathrm{N} 40.82^{\circ} \mathrm{E}$, occurrence time $=19: 30: 46.3$, magnitude; $M_{s}=$ 6.0, depth: $h=10 \mathrm{~km}$ ) occurred in the east of Turkey were taken. Information of stations is given in Table 1 . Locations of profiles between event and stations are shown on tectonic map of Anatolia [50] in Figure 3.

The amplitude spectrums of the each component have been weighted by using Equation (6), but the phase angles are untouched. In these equations, $M, K, N$ constants and the angle $\theta$ corresponding to horizontal/vertical displacement ratio have been valued as 8, 8, 4 and 0.8, respectively [2]. After, it is returned the time domain with original phase value and scaled amplitude values. The same process is reiterated for the other windowing

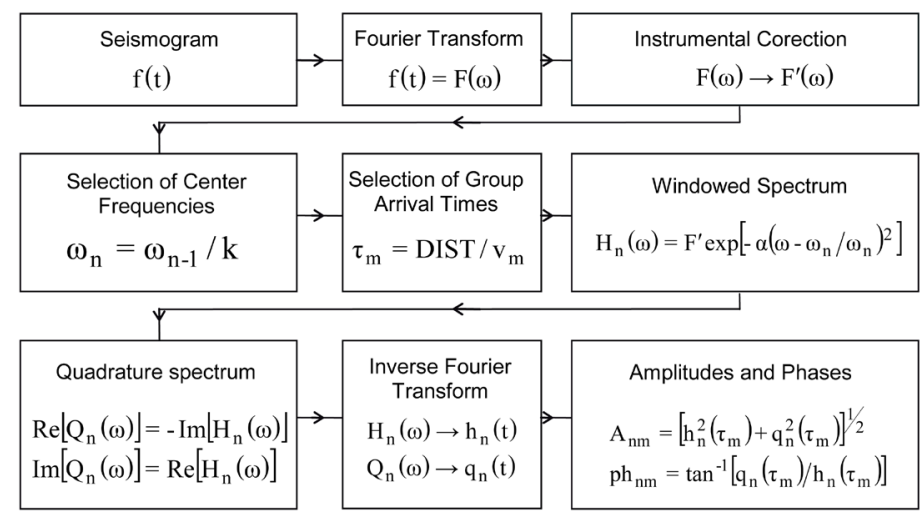

Figure 2. Flow diagram of MFT processes. 


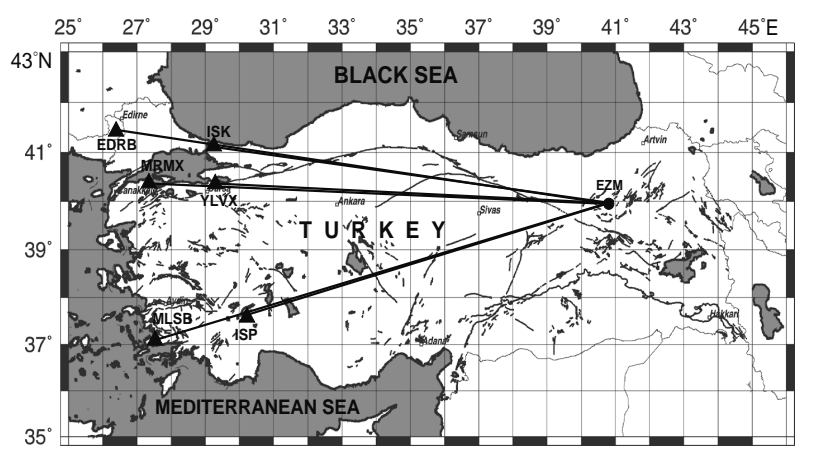

Figure 3. Location of the event $(\bullet)$ and stations $(\boldsymbol{\Delta})$ are shown at tectonic map of Anatolia [55].

Table 1. Station information used in the study.

\begin{tabular}{cccccc}
\hline \multirow{2}{*}{ Station Code } & \multicolumn{2}{c}{ Coordinates } & Epicenter $\Delta\left({ }^{\circ}\right)$ & Azimuth Az $\left(^{\circ}\right)$ \\
\cline { 2 - 3 } & $\left({ }^{\circ} \mathrm{N}\right)$ & $\left({ }^{\circ} \mathrm{E}\right)$ & 8.16 & 90 \\
YLVX & 40.34 & 29.22 & 10.07 & 71 \\
MLSB & 37.18 & 27.47 & 9.59 & 89 \\
MRMX & 40.36 & 27.35 & 7.82 & 70 \\
ISP & 37.49 & 30.31 & 8.33 & 95 \\
ISK & 41.04 & 29.04 & 10.32 & 95 \\
EDRB & 41.51 & 26.45 & & 95 \\
\hline
\end{tabular}

by selected moving interval and this process is continued by scanning all of the signals. Finally, filtered signal is obtained as the arithmetic average of values of the overlapping amplitudes. Parameters used in the discrimination filter technique for each record are given in Table 2.

Tests related to the surface wave discrimination filter technique have been denoted that window length and moving interval are significantly effect to the results [4] [5] [8] [51] [52]. According to calculations, the ratio between the window length and moving interval increases depending on the epicentral distance and this ratio has been determined in the interval of 3.95 - 4.80 for present study. Since Love wave particle motion is perpendicular to propagation direction on the horizontal plane, the tangential component is taken as real amplitude. Love waves (traces at T-components) at records applied polarization filter have been obtained perfectly because the amplitudes on the T-component are larger than the amplitudes on the Z- and R-components in all records. In this case, total effect of weighting factors has been strengthened to Love waves at some periods arrived at the station. Original and discriminated Love wave records are shown in Figure 4.

After instrumental responses were eliminated from traces by deconvolution, group velocities of discriminated Love waves have computed by MFT (Figure 2). Then the crust and upper-mantle structure for each profile between stations and event has been determined with inversion based on Hedgehog method. Theoretical and observed group velocities dispersion curves for all profiles are given in Figure 5. Maximum difference between theoretical and observed group velocities for each period is $0.05 \mathrm{~km} / \mathrm{sec}$. The crust and upper-mantle structure in Anatolia has been determined by inversion of Love wave group velocity dispersion curves (Figure 6). Density value of each layer is identical for all profiles passed similar continental paths (Figure 3). S-velocity values exhibit small changes among the profiles (Table 3).

\section{Discussion and Conclusions}

In this study, for an earthquake (EZM) occurred in eastern Anatolia, crust and upper mantle structure of Anatolia have been investigated by the inversion of discriminated Love waves group velocities for six profiles between the stations MLSB, MRMX, YLVX, ISP, ISK, EDRB which are located in western of Anatolia. Firstly, surface 

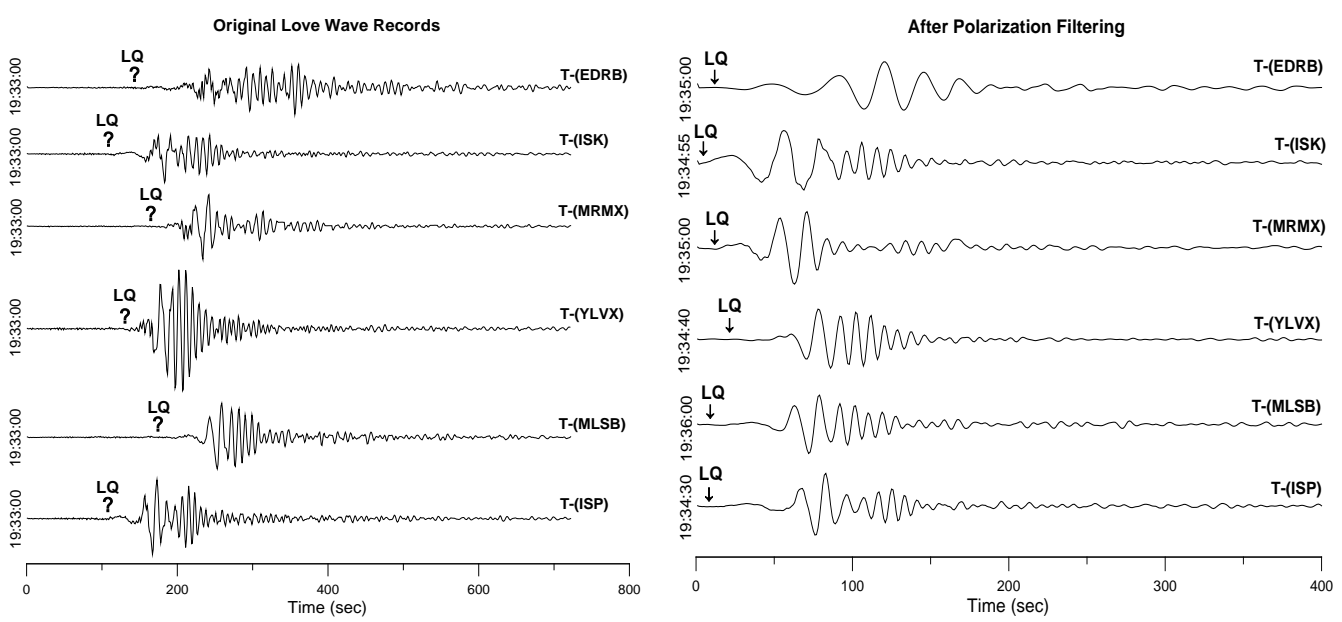

Figure 4. Original Love wave records and discriminated records after polarization filtering.
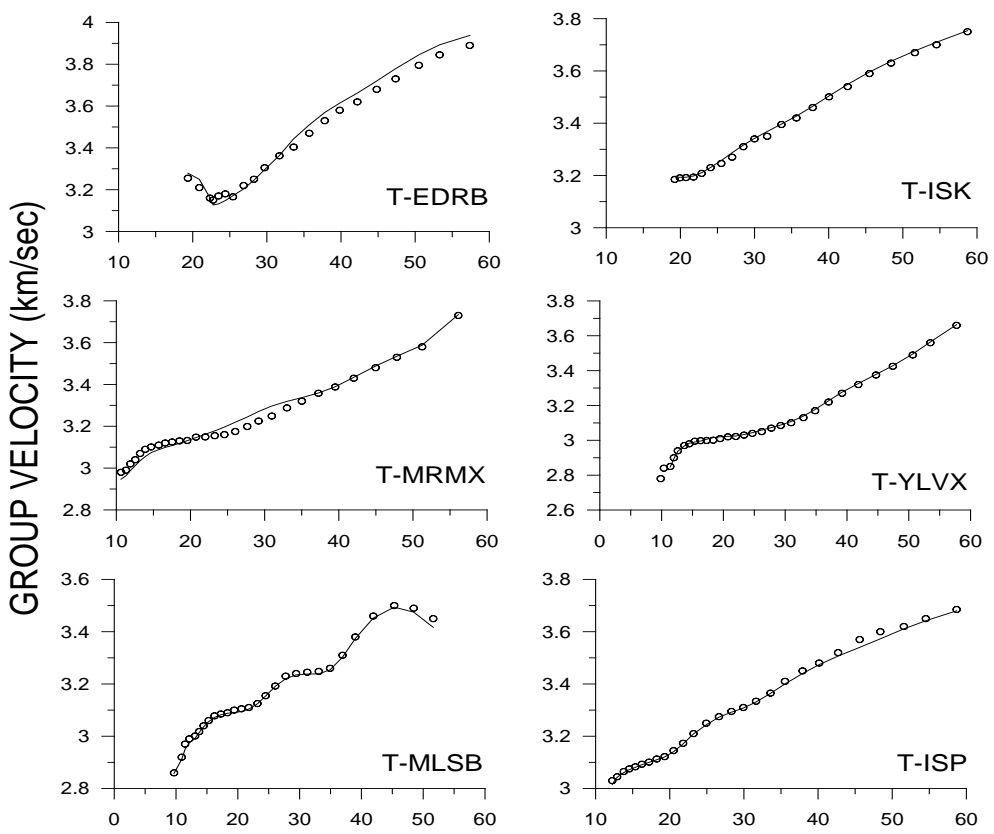

PERIOD (sec)

Figure 5. Observed (by multiple filter technique, circles) and theoretical (for the model determined from inversion, continuous line) Love wave group velocity dispersion curves for six profiles.

Table 2. Parameters used in the discrimination filter analysis.

\begin{tabular}{cccccc}
\hline $\begin{array}{c}\text { Station } \\
\text { Code }\end{array}$ & $\begin{array}{c}\text { Epicenter } \\
\Delta(\mathrm{km})\end{array}$ & $\begin{array}{c}\text { Data Length } \\
(\mathrm{sec})\end{array}$ & $\begin{array}{c}\text { Window } \\
\text { Length }(\mathrm{sec})\end{array}$ & $\begin{array}{c}\text { Window Length/Moving } \\
\text { Interval }\end{array}$ & $\begin{array}{c}\text { Smoothing } \\
\text { Operator }\end{array}$ \\
\hline ISP & 927 & 720 & 75 & 3.95 & 9 \\
YLVX & 928 & 950 & 75 & 3.95 & 9 \\
ISK & 1011 & 720 & 90 & 4.10 & 7 \\
MRMX & 1134 & 720 & 90 & 4.50 & 9 \\
MLSB & 1176 & 720 & 90 & 4.50 & 9 \\
EDRB & 1211 & 720 & 120 & 4.80 & 9 \\
\hline
\end{tabular}



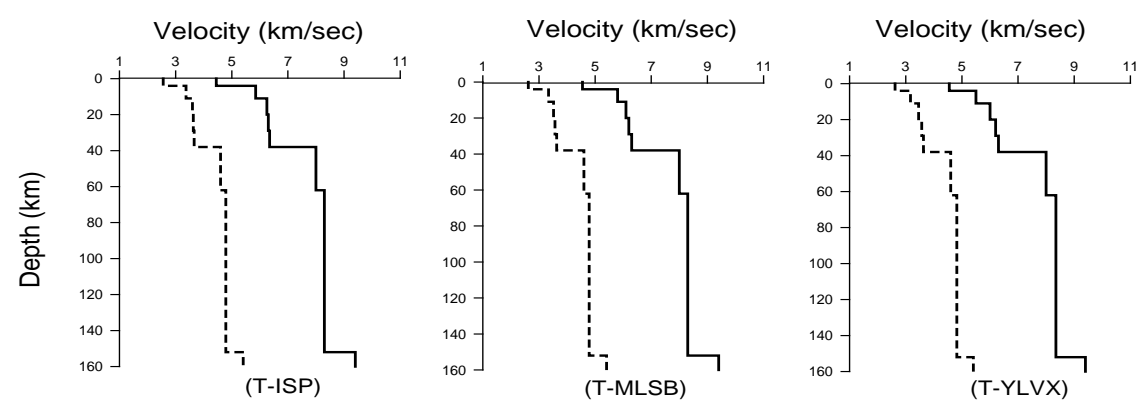

Density $\left(\mathrm{gr} / \mathrm{cm}^{3}\right)$
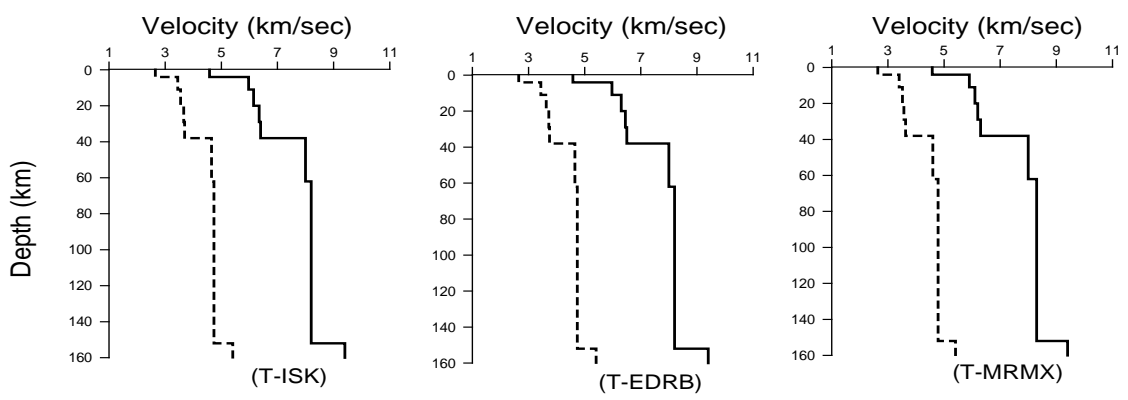

Figure 6. Variations of P- and S-waves velocities and density with depth are shown for all profiles. Dashed lines are point to the $\mathrm{S}$-wave velocity.

Table 3. Parameters of structural models obtained from the analysis for all profiles.

\begin{tabular}{|c|c|c|c|c|c|c|c|c|c|}
\hline \multirow[t]{2}{*}{ Profile } & \multirow{2}{*}{$\begin{array}{l}\text { Thickness } \\
\text { (km) }\end{array}$} & \multicolumn{2}{|c|}{$\begin{array}{l}\text { Velocity } \\
\text { (km/sec) }\end{array}$} & \multirow{2}{*}{$\begin{array}{l}\text { Density } \\
\left(\mathrm{gr} / \mathrm{cm}^{3}\right)\end{array}$} & \multirow[t]{2}{*}{ Profile } & \multirow{2}{*}{$\begin{array}{c}\text { Thickness } \\
\text { (km) }\end{array}$} & \multicolumn{2}{|c|}{$\begin{array}{l}\text { Velocity } \\
\text { (km/sec) }\end{array}$} & \multirow{2}{*}{$\begin{array}{l}\text { Density } \\
\left(\mathrm{gr} / \mathrm{cm}^{3}\right)\end{array}$} \\
\hline & & $\mathrm{P}$ & S & & & & $\mathrm{P}$ & S & \\
\hline \multirow[t]{8}{*}{ EZM-ISK } & 4 & 4.58 & 2.65 & 2.45 & EZM-MRMX & 4 & 4.58 & 2.64 & 2.45 \\
\hline & 7 & 5.97 & 3.45 & 2.55 & & 7 & 5.90 & 3.40 & 2.55 \\
\hline & 9 & 6.15 & 3.55 & 2.60 & & 9 & 6.10 & 3.52 & 2.60 \\
\hline & 9 & 6.35 & 3.66 & 2.70 & & 9 & 6.20 & 3.57 & 2.70 \\
\hline & 11 & 6.40 & 3.69 & 2.75 & & 9 & 6.30 & 3.63 & 2.75 \\
\hline & 24 & 8.00 & 4.65 & 3.15 & & 24 & 8.00 & 4.60 & 3.15 \\
\hline & 90 & 8.20 & 4.74 & 3.25 & & 90 & 8.30 & 4.79 & 3.25 \\
\hline & $\infty$ & 9.40 & 5.41 & 3.40 & & $\infty$ & 9.40 & 5.41 & 3.40 \\
\hline \multirow[t]{8}{*}{ EZM-EDRB } & 4 & 4.58 & 2.65 & $"$ & EZM-ISP & 4 & 4.45 & 2.56 & $"$ \\
\hline & 7 & 5.97 & 3.44 & $"$ & & 7 & 5.85 & 3.37 & $"$ \\
\hline & 9 & 6.30 & 3.63 & $"$ & & 9 & 6.25 & 3.60 & $"$ \\
\hline & 9 & 6.45 & 3.72 & $"$ & & 9 & 6.30 & 3.63 & $"$ \\
\hline & 10 & 6.50 & 3.75 & $"$ & & 9 & 6.35 & 3.66 & $"$ \\
\hline & 24 & 8.00 & 4.65 & $"$ & & 24 & 8.00 & 4.60 & $"$ \\
\hline & 90 & 8.20 & 4.74 & " & & 90 & 8.30 & 4.79 & $"$ \\
\hline & $\infty$ & 9.40 & 5.41 & $"$ & & $\infty$ & 9.40 & 5.41 & $"$ \\
\hline \multirow[t]{8}{*}{ EZM-YLVX } & 4 & 4.55 & 2.62 & $"$ & EZM-MLSB & 4 & 4.55 & 2.62 & $"$ \\
\hline & 7 & 5.50 & 3.17 & " & & 7 & 5.80 & 3.34 & $"$ \\
\hline & 9 & 6.00 & 3.46 & " & & 9 & 6.10 & 3.52 & $"$ \\
\hline & 9 & 6.20 & 3.57 & " & & 9 & 6.20 & 3.57 & $"$ \\
\hline & 9 & 6.30 & 3.63 & " & & 10 & 6.30 & 3.63 & $"$ \\
\hline & 24 & 8.00 & 4.60 & $"$ & & 24 & 8.00 & 4.60 & $"$ \\
\hline & 90 & 8.35 & 4.82 & $"$ & & 90 & 8.30 & 4.79 & $"$ \\
\hline & $\infty$ & 9.40 & 5.41 & $"$ & & $\infty$ & 9.40 & 5.41 & $"$ \\
\hline
\end{tabular}


wave discrimination filter based on the polarization properties has been applied to three-component records at six stations and emphasized to surface waves. As it can be seen from analysed records, the window length and hence the moving interval must be increased related to the ascending signal length [2] [4] [8]. The ratio between the window length and moving interval is determined in the interval of $3.95-4.80$ from the analysis of the records in the present study. This ratio was given as 16 for far-field $\left(\Delta>40^{\circ}\right)$ events by [2]. Later, MFT has been applied to Love wave records and the group velocities have been calculated. The structure model is taken from the average model for the whole previous database [24] [25] [31] [32] [36]-[39] [53] [54]. According to the values of the group and phase velocities for Rayleigh waves with respect to structural parameters, the dispersion data in the period ranges of $5 \mathrm{sec}$ to $150 \mathrm{sec}$ for group velocity and from $15 \mathrm{sec}$ to $150 \mathrm{sec}$ for phase velocity can be used to obtain reliable velocity structure in the depth range of 3 - $13 \mathrm{~km}$ to about $350 \mathrm{~km}$ [55]. In this study, the reliable velocity structure in the depth of $4-160 \mathrm{~km}$ has been obtained from the Love wave group velocity dispersion data in the period ranges of $10 \mathrm{sec}$ to $60 \mathrm{sec}$.

In present study, the P-wave velocities of $4.55-4.58 \mathrm{~km} / \mathrm{sec}$ in the sediment layer of $4 \mathrm{~km}$ thick have been found for all profiles. The granite basement below has $5.5-5.97 \mathrm{~km} / \mathrm{sec}$ velocity at a depth of about $4 \mathrm{~km}$ for six profiles. As a basement of upper crust, the granitic layer with a seismic velocity $6.0-6.35 \mathrm{~km} / \mathrm{sec}$ at depth of about $11 \mathrm{~km}$ might be evaluated as an upper level of lower-crust, which is more massive. Below the base of the upper crust, there is a layer with seismic velocities between $6.30 \mathrm{~km} / \mathrm{sec}$ and $6.50 \mathrm{~km} / \mathrm{sec}$ with a variable velocity gradient for all profiles and it lies at the base of the upper crust at a depth of about $29 \mathrm{~km}$. Moho depth has been found as about 38 - $40 \mathrm{~km}$ for all profiles and the S-wave velocities in the upper mantle vary between 4.60 $\mathrm{km} / \mathrm{sec}$ and $4.82 \mathrm{~km} / \mathrm{sec}$ in the depth range of about $40-150 \mathrm{~km}$. It has also been found that the mantle S-wave velocities are generally faster in the south and become slower in the north of Turkey.

The current method used in this study is based on the classical single-station method, but now we are able to combine single- and two-station measurements as well as the ambient noise and/or group speed analysis will allow us to better constrain both the crust and uppermost mantle structures. Such an approach will require much more profiles as well as a large number of surface wave measurements. With the increasing number of earthquake data from the current seismic networks in Turkey, we will be able to gather much larger numbers of reliable surface wave measurements including whole Turkey and the higher resolution images of the crust and upper mantle including anisotropic properties would be able to be obtained in the near future.

\section{References}

[1] Gal'perin, E.I. and Frolova, A.V. (1960) Azimuth-Phase Correlation for Elliptically Polarized Waves. Izvestiya Soviet Academy of Sciences, Geophysics Series, 2, 195-208. (in Russian)

[2] Simons, R.S. (1968) A Surface Wave Particle Motion Discrimination Process. Bulletin of Seismological Society of America, 58, 629-637.

[3] Shimsoni, M. and Smith, S.W. (1964) Seismic Signal Enhancement Three-Component Detectors. Geophysics, 24, 664671. http://dx.doi.org/10.1190/1.1439402

[4] Osmansahin, I., Ozer, M.F. and Sayil, N. (1994) Surface Wave Discrimination Filter Based on Polarization Properties. Geophysics, 8, 99-104.

[5] Du, Z., Foulger, G.R. and Weijian, M. (2000) Noise Reduction for Broad-Band Three-Component Seismograms Using Data-Adaptive Polarization Filters. Geophysical Journal International, 141, 820-828. http://dx.doi.org/10.1046/j.1365-246x.2000.00156.x

[6] Pinnegar, C.R. (2006) Polarization Analysis and Polarization Filtering of Three-Component Signals with the TimeFrequency Transform. Geophysical Journal International, 165, 596-606. http://dx.doi.org/10.1111/j.1365-246X.2006.02937.x

[7] Amoroso, O., Maercklin, N. and Zollo, A. (2012) S-Wave Identification by Polarization Filtering and Waveform Coherence Analysis. Bulletin of Seismological Society of America, 102, 854-861. http://dx.doi.org/10.1785/0120110140

[8] Kutlu, Y.A. and Sayil, N. (2013) A Modified Surface Wave Particle Motion Discrimination Process. International Journal of Physical Sciences, 8, 395-405.

[9] Ewing, M., Jardetzky, W. and Pres, F. (1957) Elastic Waves in Layered Media. Mc Graw-Hill, New York.

[10] Pilant, W.L. (1979) Elastic Waves in the Earth, Developments in Solid Earth Geophysics. Elsevier, Holland.

[11] Panza, G.F., Schwab, F. and Knopoff, L. (1973) Multimode Surface Waves for Selected Focal Mechanism I. Dip-Slip Sources on a Vertical Fault Plane. Geophysical Journal International, 34, 265-278. 
http://dx.doi.org/10.1111/j.1365-246X.1973.tb02396.x

[12] Panza, G.F., Schwab, F. and Knopoff, L. (1975) Multimode Surface Waves for Selected Focal Mechanism, III. StrikeSlip Sources on a Vertical Fault Plane. Geophysical Journal of the Royal Astronomical Society, 42, 945-955. http://dx.doi.org/10.1111/j.1365-246X.1975.tb06460.x

[13] Romanowicz, B.A. (1980) A Study of Large-Scale Lateral Variations of $P$ Velocity in the Upper Mantle beneath Western Europe. Geophysical Journal International, 63, 217-232. http://dx.doi.org/10.1111/j.1365-246X.1980.tb02617.x

[14] Levshin, A.L., Ritzwoller, M.H. and Ratnikova, L.I. (1994) The Nature and Cause of Polarization Anomalies of Surface Waves Crossing Northern and Central Eurasia. Geophysical Journal International, 117, 577-590. http://dx.doi.org/10.1111/j.1365-246X.1994.tb02455.x

[15] Spakman, W., Van der Lee, S. and Van der Hilst, R.D. (1993) Travel-Time Tomography of the European-Mediterranean Mantle down to $1400 \mathrm{~km}$. Physics of the Earth and Planetary Interiors, 79, 3-74. http://dx.doi.org/10.1016/0031-9201(93)90142-V

[16] Marquering, H. and Snieder, R. (1996) Shear-Wave Velocity Structure Beneath Europe, the Northeastern Atlantic and Western Asia from Waveform Inversions Including Surface-Wave Mode Coupling. Geophysical Journal International, 127, 283-304. http://dx.doi.org/10.1111/j.1365-246X.1996.tb04720.x

[17] Ritzwoller, M.H. and Levshin, A.L. (1998) Eurasian Surface Wave Tomography: Group Velocities. Journal of Geophysical Research: Solid Earth, 103, 4839-4878. http://dx.doi.org/10.1029/97JB02622

[18] Marone, F., Van der Mejide, M., Van der Lee, S. and Giardini, D. (2003) Joint Inversion of Local, Regional and Teleseismic Data for Crustal Thickness in the Eurasia-Africa Plate Boundary. Geophysical Journal International, 154, 499-514. http://dx.doi.org/10.1046/j.1365-246X.2003.01973.X

[19] Al-Lazki, A.I., Sandvol, E., Seber, D., Barazangi, M., Turkelli, N. and Mohamad, R. (2004) Pn Tomographic Imaging of Mantle Lid Velocity and Anisotropy at the Junction of the Arabian, Eurasian, and African Plates. Geophysical Journal International, 158, 1024-1040. http://dx.doi.org/10.1111/j.1365-246X.2004.02355.x

[20] Boschi, L., Ekstrom, G. and Kustowski, B. (2004) Multiple Resolution Surface Wave Tomography: The Mediterranean Basin. Geophysical Journal International, 157, 293-304. http://dx.doi.org/10.1111/j.1365-246X.2004.02194.x

[21] Pasyanos, M.E. (2005) A Variable Resolution Surface Wave Dispersion Study of Eurasia, North Africa, and Surrounding Regions. Journal of Geophysical Research: Solid Earth, 110, 301.

[22] Erduran, M., Endrun, B. and Meier, T. (2008) Continental vs. Oceanic Lithosphere beneath the Eastern Mediterranean Sea-Implications from Rayleigh Wave Dispersion Measurements. Tectonophysics, 457, 42-52. http://dx.doi.org/10.1016/j.tecto.2008.05.015

[23] Schivardi, R. and Morelli, A. (2011) EP Mantle: A 3-D Transversely Isotropic Model of the Upper Mantle under the European Plate. Geophysical Journal International, 185, 469-484. http://dx.doi.org/10.1111/j.1365-246X.2011.04953.x

[24] Bakirci, T., Yoshizawa, K. and Özer, M.F. (2012) Three-Dimensional S-Wave Structure of the Upper Mantle beneath Turkey from Surface Wave Tomography. Geophysical Journal International, 190, 1058-1076.

[25] Salaün, G., Pedersen, H., Paul, A., Farra, V., Karabulut, H., Hatzfeld, D., Papazachos C., Childs, D.M., Pequegnat, C. and the SIMBAAD Team (2012) High-Resolution Surface Wave Tomography of the Aegean-Anatolia Region: Constraints on Upper-Mantle Structure. Geophysical Journal International, 190, 406-420. http://dx.doi.org/10.1111/j.1365-246X.2012.05483.x

[26] Artemieva, I.M. and Thybo, H. (2013) EUNAseis: A Seismic Model for Moho and Crustal Structure in Europe, Greenland, and the North Atlantic Region. Tectonophysics, 609, 97-153. http://dx.doi.org/10.1016/j.tecto.2013.08.004

[27] Ozer, M.F. (1989) The Crust Structure Modeling with Converted Phases. Ph.D. Thesis, Karadeniz Technial University, Trabzon.

[28] Sayil, N. and Osmansahin, I. (2000) Investigation of Crust and Upper-Mantle Structure at the Black Sea with GroupVelocity Data. Bulletin of Seismological Society of America, 90, 870-875. http://dx.doi.org/10.1785/0119990054

[29] Koulakov, I., Tychkov, S., Bushenkova, N. and Vasilevsky, A. (2002) Structure and Dynamics of the Upper Mantle beneath the Alpine-Himalayan Orogenic Belt, from Teleseismic Tomography. Tectonophysics, 358, 77-96. http://dx.doi.org/10.1016/S0040-1951(02)00418-3

[30] Piromallo, C. and Morelli, A. (2003) P Wave Tomography of the Mantle under the Alpine-Mediterranean Area. Journal of Geophysical Research, 108, Published Online. http://dx.doi.org/10.1029/2002JB001757

[31] Biryol, C.B., Beck, S.L., Zandt, G. and Özacar, A.A. (2011) Segmented African Lithosphere beneath the Anatolian Region Inferred from Teleseismic P-Wave Tomography. Geophysical Journal International, 184, 1037-1057. http://dx.doi.org/10.1111/j.1365-246X.2010.04910.x

[32] Osmansahin, I. (1989) Determination of Crust and Upper-Mantle Structure in Anatolia and Its Neighborhood from In- 
ter-Station Response Functions of Surface Waves. Ph.D. Thesis, Istanbul University, Istanbul.

[33] Maggi, A. and Priestley, K. (2005) Surface Waveform Tomography of Turkish-Iranian Plateau. Geophysical Journal International, 160, 1068-1080. http://dx.doi.org/10.1111/j.1365-246X.2005.02505.x

[34] Hearn, T. and Ni, J. (1994) Pn Velocities beneath Continental Collision Zones: The Turkish-Iranian Plateau. Geophysical Journal International, 117, 273-283. http://dx.doi.org/10.1111/j.1365-246X.1994.tb03931.x

[35] Gök, R., Pasyanos, M.E. and Zor, E. (2007) Lithospheric Structure of Continent-Continent Collision Zone: Eastern Turkey. Geophysical Journal International, 169, 1029-1088. http://dx.doi.org/10.1111/j.1365-246X.2006.03288.x

[36] Ezen, U. (1983) Structure of the Earth Crust and Love Waves Dispersion in the North and East Anatolia. Bulletin of the Earthquake Research Institute, 43, 42-62.

[37] Canitez, N. and Toksoz, M.N. (1980) Crustal Structure beneath Turkey. Eos, Transactions American Geophysical Union, 61, 290.

[38] Mindevalli, O.Y. (1988) Crust and Upper Mantle Structure of Turkey and the Indian Sub-Continent Surface Wave Studies. Ph.D. Thesis, Saint Louis University, Saint Louis.

[39] Osmansahin, I. and Sayil, N. (1996) Pn-Wave Velocity beneath Anatolia from the First Arrivals. Bulletin of International Institute of Seismology and Earthquake Engineering, 30, 77-85.

[40] Endrun, B., Meier, T., Lebedev, S., Bohnoff, M., Stavrakakis, G. and Harjes, H.P. (2008) S Velocity Structure and Radial Anisotropy in the Aegean Region from Surface Wave Dispersion. Geophysical Journal International, 174, 593616. http://dx.doi.org/10.1111/j.1365-246X.2008.03802.x

[41] Karahan, A.E., Berckhemer, H. and Baier, B. (2001) Crustal Structure at the Western End of the North Anatolian Fault Zone from Deep Seismic Sounding. Annali Di Geopfisica, 44, 49-68.

[42] Karabulut, H., Ozalaybey, S., Taymaz, T., Aktar, M., Selvi, O. and Kocaoglu, A. (2003) A Tomographic Image of the Crustal Structure in the Eastern Marmara. Geophysical Research Letters, 30, 2277. http://dx.doi.org/10.1111/j.1365-246X.2008.03802.x

[43] Dziewonski, A.M., Bloch, S. and Landisman, M. (1969) A Technique for the Analysis of Transient Seismic Signals. Bulletin of Seismological Society of America, 59, 427-444.

[44] Bhattacharya, S.N. (1983) Higher Order Accuracy in Multiple Filter Technique. Bulletin of Seismological Society of America, 73, 1395-1406.

[45] Herrmann, R.B. and Ammon, C.J. (2004) Surface Waves, Receiver Functions and Crustal Structure, Computer Programs in Seismology, Version 3.30. Saint Louis University, Saint Louis.

[46] Valyus, V.P., Keilis-Borok, V.I. and Levshin, A. (1969) Determination of the Upper-Mantle Velocity Cross-Section for Europe. Proceedings of the USSR Academy of Sciences, 185, 3.

[47] Knopoff, L. (1972) Observations and Inversion of Surface-Wave Dispersion. Developments in Geotectonics, 13, 497519. http://dx.doi.org/10.1016/B978-0-444-41015-3.50032-X

[48] Knopoff, L. and Panza, G.F. (1977) Resolution of Upper Mantle Structure Using Higher Modes of Rayleigh Waves. Annales Geophysicae, 30, 491-505.

[49] Ludwig, W.J., Nafe, J.E. and Drake, C.L. (1970) Seismic Refraction, the Sea. Vol. 4 (Part 1), Wiley-Interscience, New York, 53-84.

[50] Saroglu, F., Emre, O. and Kuscu, I. (1992) Active Fault Map of Turkey. General Directorate of Mineral Research and Exploration, Turkey.

[51] Kanasewich, E.R. (1973) Time Sequence Analysis in Geophysics. The University of Alberta Press, Camrose.

[52] De Meersman, K., Van der Baan, A. and Kendall, J.M. (2006) Signal Extraction and Automated Polarization Analysis of Multi Component Array Data. Bulletin of Seismological Society of America, 96, 2415-2430. http://dx.doi.org/10.1785/0120050235

[53] Osmansahin, I. and Sayil, N. (2001) Near Field Travel-Time Solutions for Anatolia. Journal of the Balkan Geophysical Society, 4, 3-8.

[54] Bekler, T. and Gurbuz, C. (2008) Insight into the Crustal Structure of the Eastern Marmara Region, NW Turkey. Pure and Applied Geophysics, 165, 295-309. http://dx.doi.org/10.1007/s00024-008-0302-3

[55] Urban, L., Cichowicz, A. and Vaccari, F. (1993) Computation of Analytical Partial Derivatives of Phase and Group Velocities for Rayleigh Waves with Respect to Structural Parameters. Studia Geophysica et Geodaetica, 37, 14-36. http://dx.doi.org/10.1007/BF01613919 
Scientific Research Publishing (SCIRP) is one of the largest Open Access journal publishers. It is currently publishing more than 200 open access, online, peer-reviewed journals covering a wide range of academic disciplines. SCIRP serves the worldwide academic communities and contributes to the progress and application of science with its publication.

Other selected journals from SCIRP are listed as below. Submit your manuscript to us via either submit@scirp.org or Online Submission Portal.
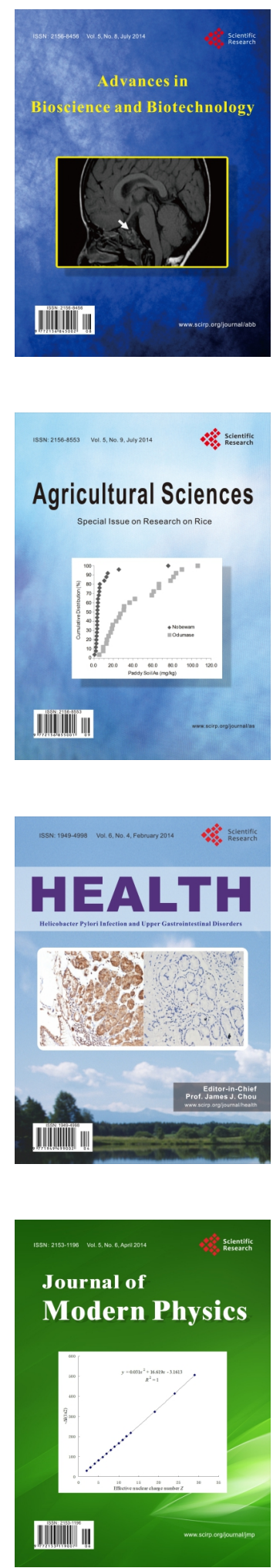
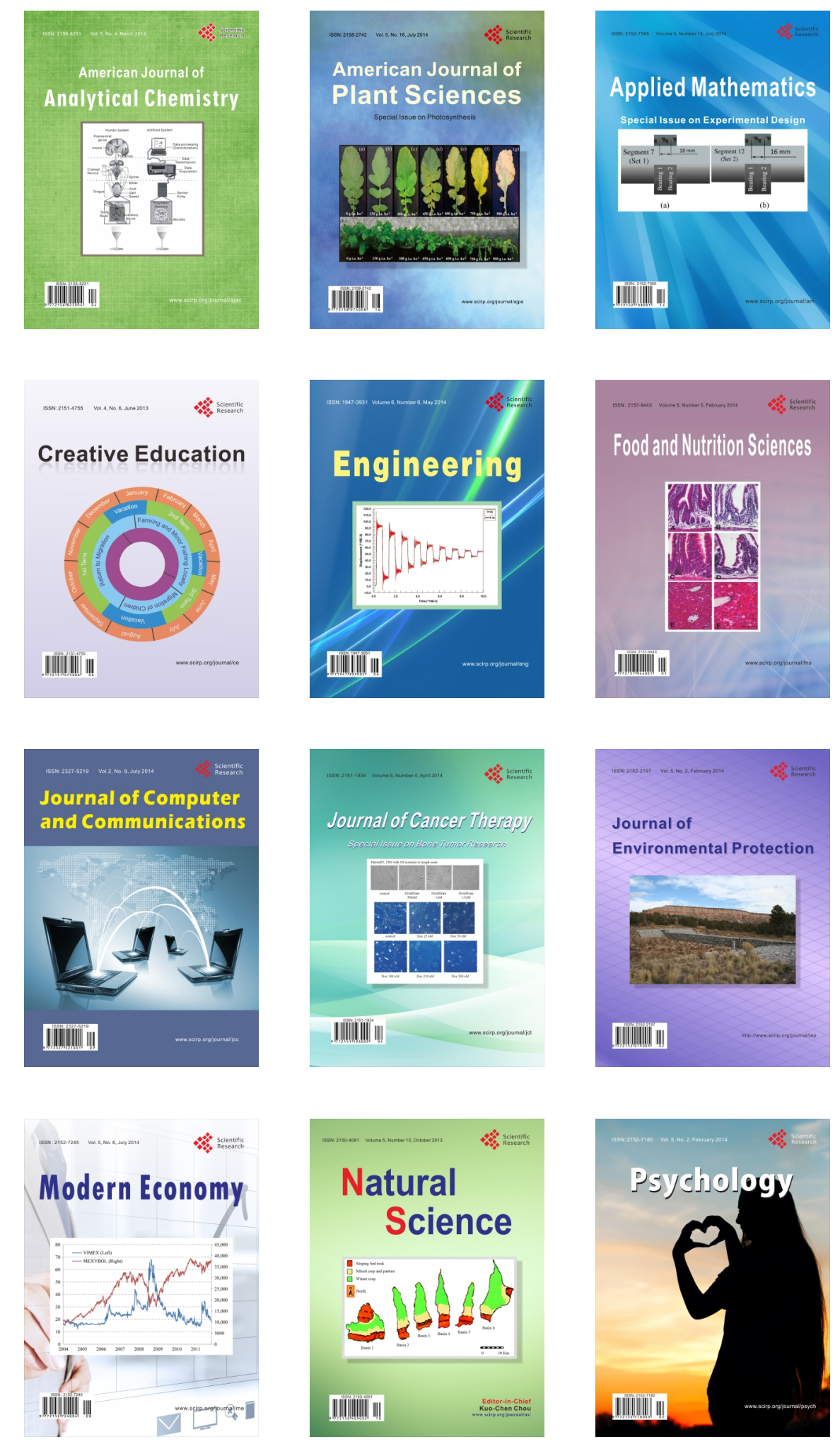